\title{
Quadrinhos nacionais no ciberespaço: uma análise de Combo Ranger nos âmbitos digital e impresso
}

Roberto Elísio dos Santos

Victor Wanderley Corrêa

Resumo: O presente artigo trata das estratégias adotadas para a criação das histórias em quadrinhos para a internet, e tem como objeto de estudo Combo Rangers. As semelhanças e diferenças entre sua versão impressa e a virtual são analisadas neste texto. A escolha dessa história se deve por Combo Rangers ter sido a história em quadrinhos brasileira pioneira a ser realizada em ambas as maneiras, impressa, e vendida em bancas e livrarias, e disponibilizada no ambiente virtual, com acesso gratuito.

Palavras-chave: história em quadrinhos; cibercultura; webcomics.

Abstract: National Comics in Cyberspace: an analysis of the Combo Ranger in the digital and printed spheres - This article discusses the strategies adopted for the creation of comic books for the Internet, and the object of study is the comic series Combo Rangers. The similarities and differences between its printed and virtual versions are analyzed in this text. Combo Rangers was chosen because it was the first Brazilian comics produced in both formats, printed and sold at newsstands and bookstores, and freely available in the virtual environment.

Keywords: comics; cyberculture; webcomics.

\section{Introdução}

Criada no final da década de 1990, Combo Rangers foi uma das primeiras histórias em quadrinhos a ganhar notoriedade por sua veiculação no ciberespaço. Feita especificamente para a internet, foi uma das primeiras a serem realizadas na mídia digital. Abordava temas considerados atuais para seu tempo e se apoiava em diversas 
outras obras midiáticas, homenageando outros produtos midiáticos apreciados pelo leitor, por meio do uso de intertextualidade.

Do ponto de vista estético, está entre as primeiras produções nacionais a se aproximar do traço das histórias em quadrinhos japonesas, denominadas mangá. Ainda assim, essa webcomic seguia a padronização artística de narrativas gráficas sequenciais publicadas no Brasil, principalmente os materiais cômicos convencionais, como as publicações das principais editoras da época (Globo, Panini e Abril).

De pouco acesso à maioria da população e com dificuldades de produção, Combo Rangers explorava os primeiros caminhos possíveis para a nona arte na internet e suas primeiras modificações e adaptações. Com característica autoral, as histórias em quadrinhos eram atualizadas semanalmente, com algumas páginas de conteúdo adicional postadas diariamente.

Quanto à disponibilidade ao leitor, não havia limites de páginas ou de permanência, atendendo à necessidade de acesso do leitor, que precisava apenas acessar o site para ler as histórias. O sucesso trouxe Combo Rangers a transitar pelas duas soluções mais comuns para a adaptação de histórias em quadrinhos: a tela do computador e o papel. Contudo, com resultados inesperados, como este trabalho se propõe a demonstrar.

Este texto é resultado de pesquisa de nível exploratório, que pretende apresentar as diferenças significativas na editoração e na arte, assim como discutir acerca das transformações decorrentes da adaptação midiática das histórias em quadrinhos, do ambiente impresso para o ambiente virtual, a fim de entender algumas das características e as distinções editoriais e artísticas das webcomics.

A análise realizada levou em consideração as inovações artísticas, a hibridação e a transposição do meio impresso ao meio digital, a abertura de material e merchandising, o uso do pastiche e da intertextualidade e as diferenças e entre o produto virtual e o impresso.

\section{As inovações em Combo Rangers}

Quando o autor, o desenhista e quadrinista Fábio Yabu, começou a desenhar seu mais famoso projeto, Combo Rangers, dificilmente ele saberia que, dentro dos padrões inovadores da arte, iniciava um trabalho de neovanguarda. Em seus estudos sobre a arte e suas inovações e transposições temporais, Huyssen (1997, p. 37) aborda as diversas discussões sobre vanguardas, desde sua origem fundada na politização, buscando mudanças, até sua morte definitiva, entre os anos de 1930 e 1940, no Ocidente. Para esse autor, a vanguarda, no sentido clássico de sua palavra, está morta. Nas palavras de Huyssen:

Hoje a obsolescência das técnicas de choque da vanguarda, sejam dadaístas, construtivistas ou surrealistas, são bem evidentes. (...) Não só a vanguarda histórica é coisa do passado, mas também é inútil tentar revivê-la sob qualquer forma. Suas invenções artísticas e suas técnicas foram absorvidas e cooptadas 
pela cultura de mass media ocidental em todas as suas manifestações, de filmes de Hollywood, televisão, design industrial e arquitetura até a esterilização da tecnologia e da mercadoria.

Em seguida, Huyssen conceitua a neovanguarda como produto de mídia de massa, destinado exclusivamente ao lazer, com emprego de técnicas cada vez mais modernas, não para chocar, ou para gerar grandes mudanças de pensamento ou cultura, mas apenas inovando em métodos e se renovando constantemente enquanto produto, em uma unificação da arte pela arte, somada às inovações tecnológicas que atendem às exigências da indústria cultural, cuja visão é centrada no lucro.

Nesse sentido, Combo Rangers, um produto da mídia digital que é acessado por um grande número de usuários da internet e possui características inovadoras, seja pelo seu pioneirismo como webcomic ou por conter referências intertextuais, pode ser considerado como uma forma de neovanguarda. Embora seja uma produção destinada ao consumo, a história em quadrinhos, impressa ou digital, é uma arte narrativa, conforme a definição de Eisner (1999, p. 7).

A tabela a seguir mostra como será feita a análise de Combo Rangers, a partir da comparação entre suas versões impressa e digital.

\begin{tabular}{|c|c|c|}
\hline Características & Versão On-line & Versão Impressa \\
\hline perenidade & $\begin{array}{l}\text { Disponível no site, indiferente de } \\
\text { datas e prazos }\end{array}$ & $\begin{array}{l}\text { Período de vendas em banca e } \\
\text { edições para colecionadores }\end{array}$ \\
\hline vendagem & $\begin{array}{l}\text { Nenhum custo, lucros por } \\
\text { inserções publicitárias e } \\
\text { mershandising }\end{array}$ & $\begin{array}{l}\text { Preço de capa no período de } \\
\text { circulação }\end{array}$ \\
\hline linguagem & $\begin{array}{l}\text { Característica de chats da internet, } \\
\text { texto conciso, com uso de } \\
\text { abreviações, repetições etc. }\end{array}$ & $\begin{array}{c}\text { Texto menos coloquial, com } \\
\text { diálogos dinâmicos trazidos da } \\
\text { versão on-line }\end{array}$ \\
\hline hiperlinks & $\begin{array}{c}\text { Ligação com elementos do próprio } \\
\text { site e de trechos em algumas das } \\
\text { histórias }\end{array}$ & $\begin{array}{l}\text { Tentativa de adaptar o recurso } \\
\text { com a linguagem dos quadros }\end{array}$ \\
\hline recursos & $\begin{array}{c}\text { Animações em Flash, sangria } \\
\text { digital, sons, cores, páginas } \\
\text { adaptáveis em tela; interatividade }\end{array}$ & $\begin{array}{l}\text { Recursos tradicionais da } \\
\text { linguagem dos quadrinhos com } \\
\text { estética do mangá }\end{array}$ \\
\hline design gráfico & $\begin{array}{c}\text { Arte experimental que prioriza } \\
\text { velocidade e flexibilidade para } \\
\text { animações; caracterização por } \\
\text { cores }\end{array}$ & $\begin{array}{l}\text { Arte mais elaborada e definida, } \\
\text { representação de elementos de } \\
\text { design da internet }\end{array}$ \\
\hline Contato com o leitor & $\begin{array}{l}\text { Constante através do site, } \\
\text { em tempo real via chat e por } \\
\text { mensagens via e-mail }\end{array}$ & $\begin{array}{c}\text { Contato por cartas e mensagens } \\
\text { via e-mail }\end{array}$ \\
\hline Formato de produção & Alternativo autoral & Industrial \\
\hline
\end{tabular}


O trabalho de Fábio Yabu é facilmente descrito como arte pela arte em sua primeira fase, desprovida de pretensões lucrativas quando o autor expunha seus desenhos, roteiros e narrativas em quadrinhos através de um site na internet. Em meados de 1990, Yabu foi um dos primeiros artistas nacionais, senão o primeiro, a realizar a empreitada e desbravar um ambiente completamente desconhecido à arte e às histórias em quadrinhos. Disponibilizado gratuitamente aos internautas, seu material era atualizado regularmente, com mais histórias e conteúdos, por meio de recursos inovadores.

As histórias contavam com uso de técnicas de arte e de computação gráfica para expandir as imagens das telas, fossem personagens saltando da imagem - técnica chamada sangria - ou a própria imagem inteira se expandindo para preencher a tela do computador. Sons eram acrescentados às imagens, que posteriormente recebiam também versão fechada em flash, com animações para as transformações de personagens em momentos específicos da trama, além do formato e do tamanho dos quadros da história em quadrinhos terem sido modificados para se adequar ao ambiente virtual.

Como um dos pioneiros na área de quadrinhos digitais, com sua obra Combo Rangers, Fábio Yabu apresentou seu trabalho ao mundo em um período de mudança, o do nascimento do ciberespaço. Segundo Lemos (2003, p. 14-19), nesse momento, surgia uma nova linguagem de convergência de meios artísticos e ferramentas comunicacionais e artes eletrônicas, bem como novas formas de relações sociais que alteravam a estrutura técnica naquele momento. A cibercultura, na visão desse autor, é "uma nova forma sociocultural" que estabelece novos modelos de sociabilidade. Com ela surgem maneiras originais de expressão, a exemplo de webcomics como Combo Rangers.

A relação de interatividade advinda pela internet iniciava um contato contínuo entre o produtor e o leitor e, mesmo em seus primórdios, apresentava as primeiras mudanças de papel entre o emissor e o receptor de uma mensagem. Yabu se aproveita dessa oportunidade para, com seus quadrinhos, iniciar uma das primeiras produções independentes nacionais na internet, utilizando-se de técnicas antes impensadas, como o novo formato de paginação, livre dos limites de uma página para impressão, com cores mais vivas, possibilitadas pelas ferramentas tecnológicas mais avançadas, e com o emprego em seus roteiros de frases coloquiais informais, menos engessadas e mais similares a uma simples conversa do cotidiano, combinada com características textuais comuns aos chats da internet de seu período.

Trata-se de uma linguagem inovadora, partindo da já distinta linguagem dos quadrinhos, a qual, conforme Canclini (2006, p. 339), é, por princípio, híbrida, heteróclita, distinta das demais, nascida na convergência entre a imagem e o texto e de elementos culturais e folclóricos, com novas ordens e técnicas narrativas, mediante a combinação artística, potencial dramático e a maneira como expressa a realidade.

Especificamente em Combo Rangers, embora não exclusivamente, seu conteúdo traz elementos mistos de cultura brasileira, como o falar característico e exemplos 
de nosso cotidiano, o que Canclini (ibid, p. 340) aponta como característica do meio artístico das histórias em quadrinhos. Em Combo Rangers encontram-se traços da cultura oriental e técnicas de produção do mangá, o quadrinho japonês, leitura de maior sucesso, no final dos anos de 1990 e começo dos anos 2000, como destaca a pesquisadora Luyten (2000, p. 191).

Sua obra ainda apresenta elementos da narrativa televisiva e inovações nos quadros narrativos, adaptados de maneira livre e descompromissada, desenvolvidos pelo autor em contrapartida às narrações clássicas de quadrinhos, feitas em escala industrial, segundo a concepção de Eisner (2005, p. 9), especialista em quadrinhos reconhecido mundialmente, cujo nome é imortalizado em uma premiação estadunidense da qual participam quadrinistas do mundo todo.

O conteúdo de Combo Rangers se baseia na famosa série televisiva juvenil Power Rangers, produto cultural da televisão estadunidense que apresenta a mesma mescla entre o ocidental e o oriental. Com colagens de cenas gravadas nos Estados Unidos e Canadá, e montagens com mesclas de cenas retiradas de tokusatsus, séries japonesas de heróis em ação com atores, monstros e robôs gigantes, material da cultura pop japonesa estudado por Luyten (2005), o programa, de apenas vinte e dois minutos semanais, mistura elementos do cotidiano norte-americano com o folclore e material cultural de massa japonês, criando uma nova forma de narração, a exemplo das obras pós-modernistas, considerada de maneira cética como pastiche por Jameson (1985, p. 19). Com início no final dos anos 1980, a série Power Rangers foi produzida até recentemente. Em um longo período de sucesso, com direito a games e dois filmes Hollywoodianos, transformou-se em um grande material de consumo.

Pode-se afirmar que Combo Rangers utiliza uma estratégia de colagem a partir da abordagem de um produto de sucesso de outra mídia, inovando ao fazer uma releitura de seu conteúdo. Essa conversa midiática, característica do hibridismo, muito comum nos meios de comunicação, remete aos estudos sobre a Cultura Midiática, realizados por Santaella (2003, p. 52), que afirma que, assim como o tradicional e o moderno, o artesanal e o industrial mesclam-se em tecidos híbridos e voláteis próprios das culturas urbanas e, como as novas tecnologias, do disponível e do descartável, demandaram um conteúdo personalizado, simbólico, heterogêneo e fugaz.

Segundo a autora, esse quadro aumentou consideravelmente os trânsitos e hibridismos pelos meios de comunicação, criando redes de complementaridades. Essa ligação de conteúdo favorecia Combo Rangers, que acompanhava o sucesso de sua série inspiradora, bem como a repercussão dos personagens e demais produtos e merchandisings, reforçando um lado mais positivo do consumo da obra e de como esta manteve sua relação com as demais mídias.

Conforme estudado por Balogh, os elementos presentes em obras similares criam a intertextualidade, ou colagem de fragmentos diversos: 
(...) A evolução tecnológica, tendo o computador como resultante central no nosso cotidiano, incide poderosamente sobre os mecanismos de elaboração, mediação e recepção dos diferentes textos da cultura. Como afirma, de forma bem humorada, Marcelo Tass, (...) há hoje uma verdadeira "promiscuidade cibernética", dado que o computador pode "casar" com um número ponderável de outros equipamentos, abrindo novas perspectivas de acesso e de criação antes inimagináveis.

Todas essas inovações incidem sobre as relações intertextuais também. Os textos se tornam não só mais acessíveis, como também muito mais passíveis de diversas manipulações do que no pretérito. (...) As manipulações também podem, como é previsível, modificar as concepções vigentes de arte. O conceito de artisticidade tradicional, centrado na obra única e original, está sendo posto em xeque. (BALOGH, 2002, p. 140)

Em seu estudo sobre seriados televisivos, Eco considera o reconhecimento da intertextualidade como positiva por parte do público, que percebe as variações e as permanências na narrativa:

O leitor de segundo nível é o que se empolga com a serialidade da série e não se empolga tanto com o retorno do mesmo (que o leitor ingênuo acreditava ser outro), mas pela estratégia de variações, ou seja, pelo modo como o mesmo inicial é continuamente elaborado de modo a fazê-lo parecer diferente. (ECO, 1989, p.129)

Sobrevivente por mais de cinco anos no ambiente virtual, Combo Rangers tornou-se sem sombra de dúvida um dos materiais mais conhecidos em produções de quadrinhos nacionais inseridos no ambiente da cibercultura. Tal conquista pôde ser obtida através da relação do autor com seus leitores.

Lévy (1999, p. 135), um dos maiores especialistas nos estudos ciberculturais, explica que a cibercultura possui gêneros próprios e diversos, mas passíveis de serem classificados por seus traços como arte, sempre partindo de uma tendência. Levy também comenta (ibid., p. 146) que grande parte das obras da cibercultura cria uma conexão com uma pós-presença de abertura material. Uma das principais características de Combo Rangers é, sem dúvida, a interatividade.

A presença do autor junto aos leitores, como se todos estivessem em um ambiente informal, de fato ocorreu durante toda a trajetória de sucesso dessa webcomic: uma tendência de se ler quadrinhos na tela do computador, unida ao modismo embalado pela série Power Rangers estadunidense e com elementos similares ao sucesso da Turma da Mônica Jovem, de Maurício de Sousa, em que o cotidiano brasileiro de adolescentes é descrito de maneira descontraída e caricata. Em sua primeira fase, com desenhos redondos, em forma de "bolinha", as cores funcionavam como quali-signo das características de cada actante, distinguindo os personagens, que têm traçado simples (Fig. 1). 


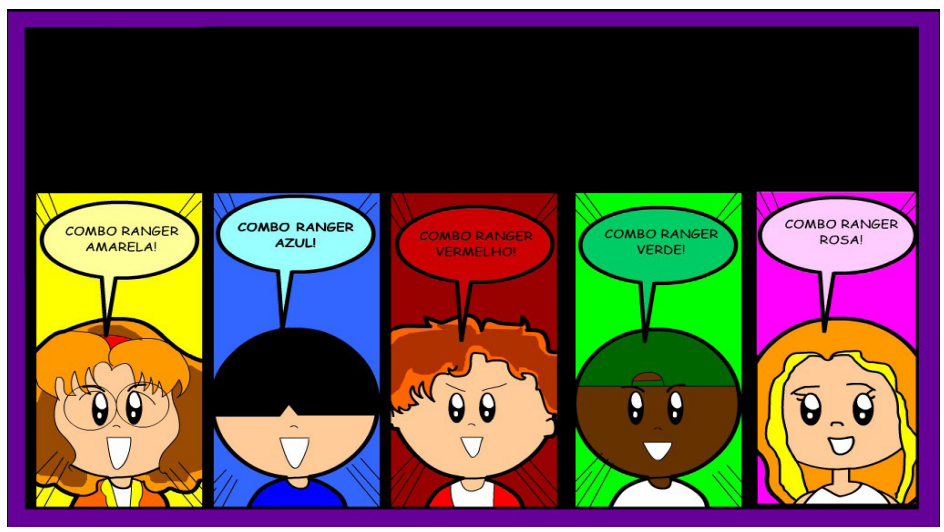

Fig. 1. Primeira fase de Combo Rangers.

Após dois anos de sucesso, Combo Rangers altera o perfil antes descompromissado com lucros, voltando-se ao mercado de consumo tamanho. Surgiram, então, materiais diversos de merchandising, como a presença de seus personagens em peças publicitárias em diversas mídias como rádio e televisão e estampados em diversos produtos escolares e infanto-juvenis como cadernos, lancheiras, adesivos, camisetas e miniaturas.

A comercialização dos elementos confirma a visão de Huyssen (1997, p. 41) sobre os elementos que permeiam a neovanguarda, presente na contemporaneidade, em que as inovações e a arte se misturam com o comércio e o lucro. Combo Rangers, transpassando os limites da mídia inicial onde nasceu, a internet, adentrou diversas outras, com resultados distintos.

A cibercultura, como explica Lemos (2003), aponta um caminho de hibridação tecnológica e cultural, com diversas mudanças em que ferramentas inteiras convergem e artes e costumes antes distintos são encontrados em um único ponto. No caso do objeto estudado, diante de um computador conectado, através do qual se tem acesso a informações e interações que ignoram as limitações tradicionais de conexão e interação.

Como foi observado anteriormente, Canclini (2006, p. 340) observa que os quadrinhos se apresentam como obra nascida da hibridação cultural, resultado da soma da arte e da literatura, da unificação entre o artesanal e o industrial, entre o popular e o erudito. A união entre a hibridação tecnológica, contida na cibercultura, e a das histórias em quadrinhos apresenta uma unificação entre meio e arte, prosseguindo por um rumo de hibridação ainda maior, em que a expressão cultural moderna se adapta à sociedade de hoje, transformando o quadrinho do virtual, como Combo Rangers, em uma distinta expressão de arte e comunicação contemporânea.

A cibercultura trouxe mudanças na forma de leitura, com o advento de livros e textos on-line, como afirma Santaella (2003, p. 128), em seus estudos sobre a cultura das mídias. A emergência da comunicação global, pela participação de todos os processos 
de comunicação, levou a mudanças no papel tanto do elaborador como do receptor dos textos a partir da mediação do computador. Também teórico da cibercultura, Lemos (2003, p.15-16) acrescenta que o conteúdo divulgado pela internet se globaliza, integra-se ao cotidiano e se espalha pelo mundo afora, ignorando seus limites territoriais.

Temos, em Combo Rangers, de Yabu, um exemplo prático das ideias de ambos os autores acima citados, em que o limite da obra on-line deixou de ser somente no nosso país para circular por todo o mundo, em discussões sobre as mirabolantes aventuras dos personagens. O material de Yabu nasceu e convergiu com o meio digital, a internet, adquirindo traços e características distintas. As histórias em quadrinhos em questão trouxeram a soma de elementos culturais populares com estratégia similar à de outras mídias, baseando-se no sucesso junto ao público, refletindo um momento de busca por conteúdo similar, pela repetição, característica da indústria cultural. A animação de Combo Rangers usa recursos inovadores e expansão da linguagem das histórias em quadrinhos: as linhas cinéticas, usadas como recurso estilístico em mangás e animações japonesas representam movimentos (Fig. 2).

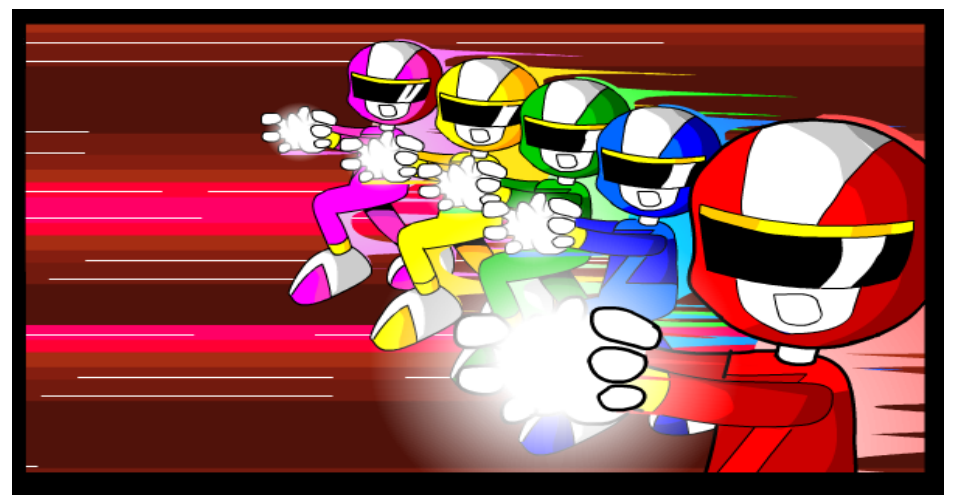

Fig. 2. PAnimação de Combo Rangers fase "Zero".

É possível dizer que Combo Rangers se distancia de sua época de concepção e se transforma, do gênero artístico híbrido ao qual as histórias em quadrinhos pertencem, em uma obra completamente nova, inicialmente desprovida de características de consumo e distinta das demais obras de histórias em quadrinhos de seu tempo.

Devido à integração da cibercultura ao cotidiano e ao crescente número de pessoas conectadas à internet, é possível afirmar que grande parte do sucesso de Combo Rangers adveio da facilidade com que os leitores interagiam com o próprio autor, Yabu. Além disso, a leitura constante dos internautas não conhece os limites de editoração encontrados na publicação periódica no gênero quadrinhos, normalmente mensal. O formato da obra digital também pôde quebrar determinadas barreiras quando comparado à leitura convencional. 
Segundo Lévy (1999, p. 148), a pragmática da comunicação no ciberespaço é distinta da comunicação convencional, encobrindo dois fatores: a totalização, por intenção pelo autor, e a totalização, por extensão pela gravação. Lévy explica que a comunicação da cibercultura segue um esquema abstrato distinto, baseado na proliferação sem limites, na multiplicidade móvel dos centros em rede aberta, no fervilhamento das hierarquias entrelaçadas e da dinâmica autopoética e auto-organizada de populações mutantes que se estendem, criam, transformam um espaço qualitativamente variado.

Para Lévy, a obra da cibercultura participa desses rizomas, está conectada à ideia de participação de pessoas e sua adesão aos fluxos de dados, que chamamos hipertexto, ou o texto que fala de si em um metamundo virtual em metamorfose perpétua em que, a cada participante, uma nova ligação de conteúdo qualitativo, como um texto coletivo, se escreve.

\section{Limitações da versão impressa}

Ao converter a obra de Yabu ao formato convencional, houve perda dessas características diferenciadas, não encontradas no meio impresso, o que resultou na resistência por parte do público. As cores encontradas na computação gráfica, reduzidas às paletas de impressão de seu período, não mantinham o mesmo aspecto, não havia o contato com o autor ou como conversar automaticamente com outros leitores, criando relacionamentos entre fãs. A competição com o próprio material on-line, os custos de sua produção e valor de mercado frente à possibilidade de encontrar o mesmo material por meios on-line, de contato interativo, ainda que limitado, condenaram ao fracasso a conversão das histórias do digital para o formato impresso editorial. A versão impressa passou a contar com o visual dos quadros e na formatação encontrada na internet, possuía traços mais trabalhados e novas formas de colorização baseadas nos quadrinhos digitais (Fig. 3).

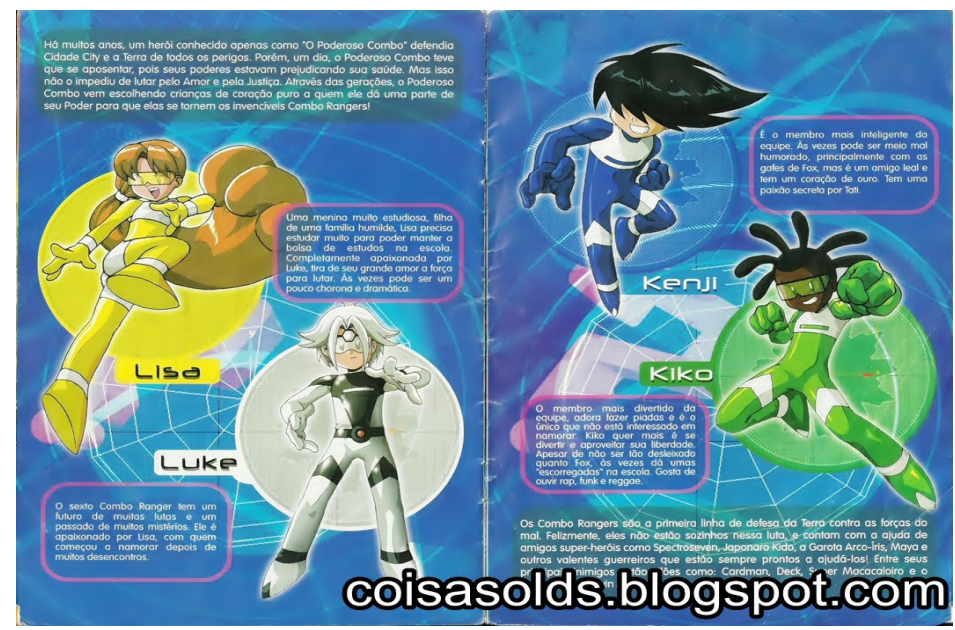

Fig. 3. Combo Rangers na versão impressa. 
Dotada de uma arte mais agradável, com um traço mais elaborado, a versão impressa dos quadrinhos aproveitou os requintes inovadores da linguagem das webcomics e do quadrinho autoral. Ainda assim, a primeira versão impressa, composta de doze edições publicadas pela Editora JBC, não atingiu as vendas esperadas. A segunda versão, da Editora Panini, conquistou melhor aceitação, principalmente por sua distribuição em âmbito nacional, com preço acessível, e sem a competição com a versão digital.

O aprimoramento concedido à versão impressa pela Editora Panini renovou cores e roteiros, quando comparada à versão anterior da JBC, conquistando importância maior para os colecionadores e fãs, principalmente pela evolução do estilo gráfico de Fábio Yabu e nas suas histórias e temas, evoluindo de histórias infantis para infanto-juvenis, diminuindo a sátira, mas sem perder o encanto original. Na versão impressa houve a tentativa de transportar as cores online, assim como a sangria em falas e imagens, tal qual na versão digital (Figs. 4 e 5).

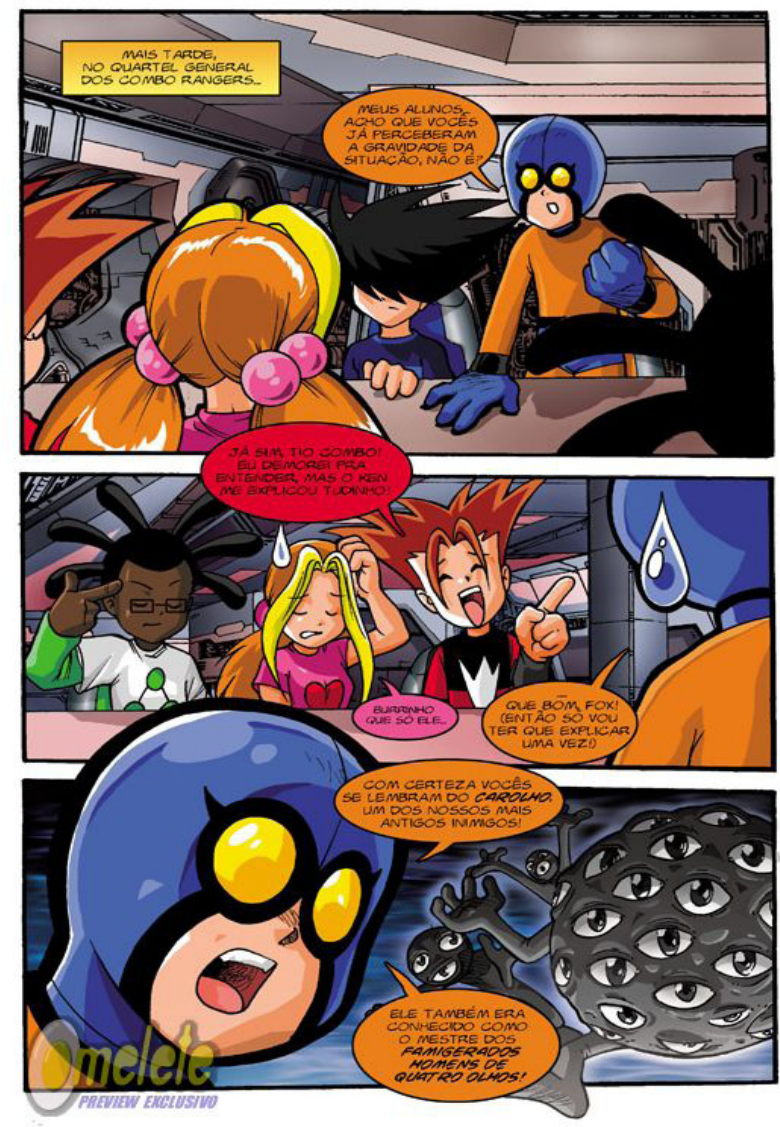




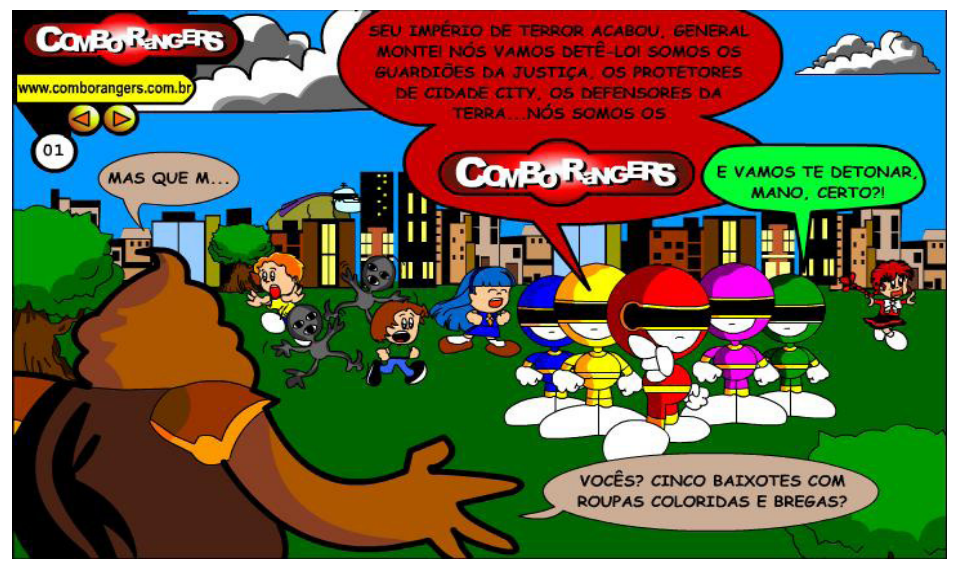

Figs. 4 e 5. Página impressa e a primeira fase na internet.

\section{Considerações finais}

Combo Rangers, obra nascida na internet e divulgada pela rede, ao ser impressa, perde a vantagem de sua disponibilidade de leitura ocasional para se tornar um objeto de coleção impressa, como os demais quadrinhos de publicação tradicional. O formato impresso impede a transposição completa de suas inovações técnicas e a construção de histórias com base no relacionamento entre o autor e os fãs.

Suas versões impressas merecem atenção, sobretudo devido à sensibilidade diante dessa diferença de mídia e resultados entre obra de autor e trabalho editorial industrial. Vale observar também como a adaptação de recursos digitais para um formato impresso permitiu o desenvolvimento de estéticas diferentes, exclusivas, mesmo com tentativa de fazer a transposição de elementos do ambiente virtual ao meio impresso.

Seu avanço também evidencia elementos inovadores aos quadrinhos brasileiros e mudanças significativas junto a autores em busca de abertura além do espaço editorial impresso disponível, divulgando sua arte com baixos custos. Os recursos de Combo Rangers, quando comparados com sua versão impressa, nos mostram que as webcomics oferecem ferramentas aos autores e editoras que expandem a linguagem dos quadrinhos.

Combo Rangers é um exemplo da contraposição de dois modos de produção e veiculação de histórias em quadrinhos na atualidade. Se o meio impresso, tradicional, ainda é o mais aceito pelos leitores, ele exige adequar a criação artística às necessidades do mercado, devido aos custos envolvidos. Essa característica da indústria editorial limita as inovações estéticas e narrativas imaginadas pelos artistas, uma vez que o critério mercadológico prepondera. Já o meio digital amplia as possibilidades de narrar histórias com sequências de imagens e textos ao permitir o uso de recursos como o som 
e a animação e a interação entre artistas e leitores. Mas ainda não permite viabilizar economicamente a realização em larga escala de quadrinhos, possibilitando que seus autores se sustentem com suas obras.

Roberto Elísio dos Santos é professor da Escola de Comunicação e do Programa de Pós-graduação em Comunicação da Universidade de São Caetano do Sul (USCS), pós-doutor em Comunicação pela ECA-USP e vicecoordenador do Observatório de Histórias em Quadrinhos da ECA-USP.

roberto.elisio@uscs.edu.br

Victor Wanderley Corrêa é mestre em Comunicação pelo Programa de Pós-graduação em Comunicação da Universidade Municipal de São Caetano do Sul (USCS) e bolsista Capes.

victor.ops@gmail.com

\section{Referências}

BALOGH, Anna Maria: O discurso ficcional da TV. São Paulo: Edusp 2002.

CANCLINI, Nestor García. Culturas Híbridas - estratégias para entrar e sair da modernidade. São Paulo: Edusp, 2006.

ECO, Umberto. Sobre os espelhos e outros ensaios. Rio de Janeiro: Nova Fronteira, 1989.

EISNER, Will. Quadrinhos e Arte Sequencial. São Paulo: Martins Fontes, 1999.

Narrativas Gráficas. São Paulo: Devir, 2005.

HUYSSEN, Andreas. Memórias do modernismo. Rio de Janeiro: UFRJ, 1997.

JAMESON, Fredric. Pós-modernidade e sociedade de consumo. Revista Novos Estudos CEBRAP, n. 12, jun/1985.

LEMOS, André. Olhares sobre a cibercultura. Porto Alegre: Sulina, 2003.

LÉVY, Pierre. Cibercultura. São Paulo: Editora 34, 1999.

LUYTEN, Sonia M. B. Mangá, o poder dos quadrinhos. São Paulo: Hedra, 2000.

Cultura pop japonesa. São Paulo: Hedra, 2005.

SANTAELLA, Lucia. Culturas e artes do pós-humano: da cultura das mídias à cibercultura.

São Paulo: Paulus, 2003. 
YABU, Fábio. Combo Rangers Revolutions, São Paulo, JBC Editora, n. 1- 3, out-dez/ 2000.

Combo Rangers, São Paulo, JBC Editora, n. 1-12, jan-dez/ 2001.

Combo Rangers, São Paulo, Panini, n. 1- 10, jan-out/ 2003-2004.

Imagens extraídas do site: http://comborangers.com.br/ (Acesso em: 27/05/2013)

Artigo recebido em julho e aprovado em setembro de 2013. 